\title{
DE LIBROS Y BIBLIOTECAS. EJERCICIOS DE REFLEXIÓN, BALANCE DE UNA INVESTIGACIÓN
}

\author{
Verónica MATEO RIPOLL \\ Universidad de Alicante
}

\begin{abstract}
Resumen
La Historia del Libro y de las Bibliotecas es una de las líneas de investigación mejor cultivadas de un tiempo a esta parte. Pero, si los patrimonios particulares han gozado de gran atención, las bibliotecas institucionales no han corrido la misma suerte. Acercarnos a ellas a través de la Biblioteca del Seminario de san Miguel de Orihuela ha sido el objetivo de este artículo; en el cual reflexionamos y damos a conocer el modo en que hemos procedido para conocer la cultura que se refugia en sus estantes, a partir de la descripción y catalogación de los ejemplares comprendidos entre los inicios de la imprenta y 1600 .
\end{abstract}

\begin{abstract}
The book and the library have traditionally provided us with one of the best lines of historical investigation. But whereas the private written collections have been the object of great attention, public or institutional libraries have not enjoyed the same consideration. Therefore the object of this article is to draw attention to the latter through the «Miguel de Orihuela Seminary Library» and after some deliberation to make known the method which we have applied in order to learn about the mass of cultural information hidden on its shelves, concentrating on the description and classification of original volumes produced when printing was in its infancy at about 1600 .
\end{abstract}

En un artículo publicado en el $\mathrm{N}^{\circ} 4$ de la Revista de Historia Moderna. Anales de la Universidad de Alicante, François López hacía un balance del estado de las investigaciones en torno al mundo del libro. Corría el año 1984 y entre la bibliografía citada figuraba una serie de trabajos, algunos hoy superados pero no por ello menos válidos. Rememoraba la labor de Pérez Pastor respecto a las imprentas de Madrid, Medina del Campo o Toledo; las contribuciones del canario Millares Carlo; la tesis de Berger para un conocimiento de la lectura y los lectores en la Valencia del Renacimiento; o las producciones de Aguilar Piñal. En el mismo escrito abogaba por una Historia del Libro integrada, donde su estudio no se redujese únicamente a la copia 
del pie de imprenta y la descripción del impreso; un conocimiento de la realidad política, económica y social nos ayudaría a comprender problemas inherentes a la impresión y edición de los textos, al comercio de los mismos, a las mentalidades, a la educación, a las modas y modos de comunicación y, en definitiva, a descifrar la historia cultural de los siglos XV a XVIII, en la que el libro es pieza clave del engranaje '.

Quince años después cabe plantearnos si han sido superadas las carencias historiográficas en este sector. Un breve repaso a las investigaciones realizadas durante el último quindenio nos desvela que esta parcela ha recibido un fuerte estímulo y que goza de buena salud ${ }^{2}$. Como se puso de manifiesto en el coloquio que tuvo lugar en Madrid, en La Casa de Velázquez en mayo de 1997, sobre Los Libros de los Españoles en la Edad Moderna, la cultura material de las élites durante este periodo, y más concretamente el estudio de sus bibliotecas, es una de las líneas de investigación que mayor relevancia está cobrando de unos añosa esta parte.

Pero si los patrimonios librarios particulares han gozado y gozan -en términos cuantitativos- de gran atención, las librerías institucionales no han corrido la misma suerte. Este hecho ha motivado que los datos que actualmente poseemos sobre esta sección del mundo del libro en el Antiguo Régimen, nos proporcionen una visión amplia, pero polarizada en favor de los primeros $\mathrm{y}$, por lo tanto, algo soslayada; toda vez que los lectores tenían acceso a los libros más allá de sus bibliotecas personales y que -comparativamente- sean menores los estudios sobre las librerías institucionales, que cubrieron buena parte de sus necesidades bibliográficas. El motivo de estas carencias radica, en buena parte, en que intentar hoy día su reconstrucción no siempre resulta fácil. Las principales dificultades sobrevienen por la diversidad de factores que intervinieron en la formación de sus fondos librarios; dado que, tal y como han llegado hasta la actualidad, son el producto de sucesivas aportaciones particulares e institucionales; fruto éstas últimas, a su vez, de segmentaciones y nuevas reincorporaciones a consecuencia de procesos históricos tales como la expulsión de la Compañía de Jesús o la desamortización de las órdenes religiosas, principalmente ${ }^{3}$. En cualquiera de los casos, el estudio de sus fondos bibliográficos e inferir resultados -en función de las posibilidades que nos ofrezcan y la generosidad de la documentación-requiere desandar el camino por el que llegaron a nosotros ${ }^{4}$.

1. López, F. «Estado actual de la Historia del Libro en España» en Revista de Historia Moderna. Anales de la Universidad de Alicante, $\mathrm{N}^{\circ}$ 4. Alicante, 1984. Pp. 9-22.

2. Sobre esta cuestión nos remitimos a M. Peña Díaz, «Cataluña en el Renacimiento: Libros y lenguas», Ed. Milenio, Lleida, 1996 y, en concreto, al capítulo «Los historiadores y el libro», donde este autor efectúa un excelente resumen sobre la historiografía nacional e internacional de la cultura del libro, en toda su extensión. Para la bibliografía de los últimos veinte años, véanse pp. 59-63 y 70-76.

3. Llama la atención sobre este mismo asunto O. Rey Castelao en su artículo «Las Bibliotecas institucionales en la Galicia de fines del Antiguo Régimen» en Fernández Albaladejo, P. y Ortega López, M. (eds.) Antiguo Régimen y Liberalismo. Homenaje a Miguel Artola. 3. Politica y cultura. Alianza Ed.Univ. Autónoma de Madrid. Madrid, 1995, pp. 583-594.

4. Mateo Ripoll, V. y García Gómez, M.L. «Algunos apuntes en torno a las bibliotecas institucionales. Las bibliotecas jesuíticas en el ámbito hispano». Comunicación presentada al Congreso Internacional El His- 
En relación con este último propósito, el de rastrear o historiar esos fondos librarios, es donde hemos de insertar nuestro trabajo sobre la Biblioteca del Seminario de san Miguel de Orihuela ${ }^{5}$; una de las dos bibliotecas de excepción con la que cuenta la capital de la Vega Baja del Segura. Pero si sobre la «Fernando de Loazes» tenemos noticias -merced no sólo a diversas publicaciones, sino a la labor de catalogación de sus fondos impulsada por la Consellería de Cultura, Educación y Ciencia ${ }^{6}$ - la del instituto eclesiástico no ha gozado de igual suerte, siendo desconocida hasta la fecha.

Este hecho no dejó de motivarnos dado que, si la significación de este centro fue notable durante la Edad Moderna -y no sólo en la ciudad sino en toda la Diócesis y aún en algunas otras cercanas, especialmente por la calidad de los estudios que ofrecía- su biblioteca debía estar a la altura de esa condición. Y es que una de las novedades más significativas en el ámbito cultural y educacional en Orihuela durante el siglo XVIII, vendría dada por el establecimiento del Seminario de san Miguel en la década de los años cuarenta ${ }^{7}$. Signo inequívoco de reactivación de los decretos tridentinos sobre la formación del clero, cuyo programa de estudios fue considerado como modelo de otros establecimientos en el ámbito nacional, como sucedió con el de Salamanca ${ }^{8}$. Respecto a la docencia, un par de años después de ser inaugurado, el Consejo de Castilla determinó completar y aumentar la función docente del Seminario, legalizando la situación de sus profesores, que quedarían integrados en el Claustro General de la Universidad de Orihuela; al tiempo que los colegiales tendrían la oportunidad de obtener grados académicos, mediante las correspondientes reválidas".

Pero si el programa disciplinar y plan de estudios de san Miguel se divulgó -merced a su publicación por vez primera en Madrid en $1744^{10}$-, la realidad de su

panisno angloamericano: sus aportaciones, problemas y perspectivas sobre Historia, Arte y Literatura españolas (siglos XVII-XVIII). Organizado por el Departamento de Historia Moderna de la Universidad de Córdoba y Cajasur. Córdoba, 9 a 14 de septiembre de 1997. (En prensa).

5. Mateo Ripoll, V. La Cultura de las Letras. La Biblioteca del Seminario de san Miguel de Orihuela en la Edad Moderna Tesis doctoral inédita, leída en la Facultad de Filosofía y Letras de la Universidad de Alicante el 28/V/1999 y evaluada con la máxima calificación.

6. Muestra de esta labor de catalogación es el Catàleg Col.lectiu del Patrimoni bibliogràfic valencià [CDROOM].- $2^{a}$ ed.- Consellería de Cultura, Educació y Ciencia. Biblioteca Valenciana. Valencia, 1995.- 1 CD.

7. Sobre el Seminario de Orihuela véase V.V.A.A. Orígenes del Seminario de Orihuela 1742-1790. Libro-Catálogo de la exposición con el mismo título. Caja de Ahorros del Mediterráneo-Obispado Orihuela Alicante. Murcia, 1992.

8. Martín Hernández, F. y J. Los Seminarios españoles en la época de la llustración. Ensayo de una pedagogía eclesiástica. CSIS, Madrid, 1973. Pp. 79.

9. Martínez Gómis, M. La Universidad de Orihuela 1610-1807. Un centro de estudios superiores entre el Barroco y la llustración. Inst. cultura «Juan Gil-Albert» de la Diputación de Alicante, et al. Alicante, 1987. 2 vols. Vol. II, Pp. 134.

10. Descripción, Constituciones y Ordenanzas para el régimen, y gobierno del Colegio de dos Seminarios, fundado en la ciudad de Orihuela ... por ... Juan Elías Gómez de Terán. El primer Seminario con el título de la Purissima Concepción de Nuestra Señora.., y este mismo agregado al Seminario,... con el titulo del archangel San Miguel... Madrid, en la oficina de Antonio Marín, 1744. 
aplicación nos era ignota. Las pérdidas de los Archivos Diocesano y del Seminario, hoy prácticamente inexistentes, hacía muy difícil contrastar como iría evolucionando la institución, los estudios y los textos. Además de las informaciones extraídas de las certificaciones de méritos de algunos estudiantes, una buena aproximación podía efectuarse desde su biblioteca; la cual debía constituir un sólido apoyo en los estudios que se impartían, al tiempo que ángulo nuevo desde el que examinar la institución. Con este posicionamiento emprendimos nuestro estudio, en la creencia de que nos permitiría adentrarnos un poco mejor en la realidad del Seminario de san Miguel. Sin embargo, como sucede a lo largo de la marcha de una investigación, las primitivas ideas fueron pronto desplazadas por otras, e incluso éstas revisadas en terceras ocasiones; en tal suerte que determinamos hacer tabula rasa de las ideas y los conocimientos previamente adquiridos, elevando la biblioteca al centro de la investigación y dejando que ella misma nos fuera dando las pautas y los elementos para juzgar, si fuera el caso, en qué medida representaba a la institución que hoy día la alberga y si las obras que contiene eran, a su vez, significativas de las líneas pedagógicas, ideológicas y culturales que parecían deducirse de la oficialidad de sus Constituciones o si, por el contrario, revelarían otras orientaciones.

En el intento por cubrir esta faceta de la investigación, pronto comprendimos la complejidad de la Biblioteca del Seminario, que se transformaría en una suerte de laberinto, donde los libros se convertirían en nuestros únicos interlocutores. Una vez instalados en el sótano del centro -que lo transformamos en nuestro taller- $y$, ante la ausencia de instrumentos de descripción de la librería, decidimos comenzar por la catalogación de los ejemplares, para intentar tener una base medianamente organizada desde la cual partiera la investigación; acotando la cronología de las obras al periodo comprendido entre los inicios de la imprenta y 1600. Para ello adoptamos las directrices que marcaba la Norma -conocida como I.S.B.D.A ${ }^{11}$ - así como las pautas que para el territorio español se seguían al hilo del Catálogo Colectivo del Patrimonio Bibliográfico Español, de modo que nuestro trabajo tuviese el rigor y la base científica deseados. Con una precisión casi quirúrgica fuimos describiendo los libros, tras su búsqueda y criba entre unos 10.000 que, aparentemente ordenados, podrían corresponderse con los del periodo consignado ${ }^{12}$. Pero esa catalogación fue más amplia de lo preceptivo, ya que no se trataba de un trabajo puramente bibliográfico, debíamos intentar reconstruir la historia de la biblioteca

11. I.S.B.D.A (Descripción Bibliográfica Internacional Normalizada para Publicaciones Monográficas Antiguas) Madrid, ANABAD y Arco/Libros. Madrid, 1993; Para algunas cuestiones complementarias nos hemos servido de las Reglas de Catalogación. Edición refundida y revisada. Ministerio de Cultura-Dirección Gral. del Libro, Archivos y Bibliotecas. Madrid, 1995.

12. En 1992, año en que comenzamos esta investigación, los libros se hallaban depositados en estanterías de madera y antiguos armarios-librería colocados en un recinto de unos $200 \mathrm{~m}^{2}$, en los sótanos del edificio. Dicho espacio se encontraba en condiciones similares -tanto ambientales como estructurales- a las que se mantuvo tras la devolución de la librería al Seminario después de la Guerra Civil. Los libros, dispuestos por materias por esas fechas, a duras penas mantenían la reordenación. 
-al menos una pequeña parte- a partir de esos mismos ejemplares; luego no ahorramos esfuerzos en los detalles de las descripciones, ya que podrían ser muy útiles a la larga.

Y es que una de nuestras mayores preocupaciones en la elaboración de esta tesis ha sido no poder contar con el apoyo documental necesario; lo que nos hubiera dado las pautas, o al menos algunas, de formación y consolidación de la librería. En un más difícil todavía, la biblioteca no conserva en la actualidad ningún libro-registro de entradas, compras, préstamos, inventarios temporales o pautas y normas para la adquisición de ejemplares. Por otro lado, el Archivo del Seminario hoy por hoy no existe; de ahí que ese registro fuese, al mismo tiempo, un punto de partida esencial y necesario para esa reconstrucción.

La historia de la Biblioteca de san Miguel y la del propio centro sigue presentando en la actualidad dudas razonables, en parte porque los datos proporcionados por las crónicas y bibliografías locales -algunas de credibilidad cuestionable- adolecen de una visión crítica al respecto. Salvo raras excepciones, se reducen a un trasnochado panegírico, que ha dado lugar a una leyenda de oropel de idílicos contornos sobre lo que antaño fuera la biblioteca y que la Guerra Civil española se encargó de destruir ${ }^{3}$. Este condicionante precisaba ser matizado y ponderado toda vez que, si bien el conflicto bélico afectó a los fondos bibliográficos -como en otros muchos lugares ${ }^{14}-$ no lo hizo en la medida que se venía creyendo. Como ha sido puesto de relieve por algunos autores ${ }^{15}$, la decisión de las autoridades republicanas alicantinas, en los primeros meses de la contienda, de agrupar todo el patrimonio artístico y bibliográfico en un palacete de la ciudad-incluidos los fondos de san Miguel que habían sido incautados a la Diócesis- antes bien, los preservó frente a lo que pudo haber sido una destrucción mayor. Pese a las precauciones de Justo García Soriano, quien estuvo al frente de su gestión, hemos constatado algún que otro trasvase o distracción de libros entre las diversas bibliotecas allí reunidas

13. Sirva, por reducirnos a un único ejemplo, el párrafo siguiente: «La Biblioteca del Seminario Conciliar de san Miguel (...) ha sufrido extraordinarios descalabros y pérdidas valiosas. Sus fondos se quemaron, en parte, por los marxistas, en los primeros dias de su dominio, pero otros muchos perecieron en los diferentes trasiegos y forzado abandono padecido antes y después de la liberación». Cfrr. en Albert Berenguer, I. «Las secciones de incunables en las Bibliotecas de Alicante y Orihuela» en Revista del Instituto de Estudios Alicantinos, $\mathrm{N}^{\circ} 14$ (1975), pp. 25-41.

14. Sobre este aspecto J. Martín Abad, comenta las destrucciones sufridas durante las guerras de la Independencia y la Civil española, y los efectos que tuvieron sobre las colecciones de las Bibliotecas Arzobispales de Toledo y Valencia, o la Abadía benedictina de Monserrat, entre otras, Cfr. en Martín Abad, J. Los incunables de las Bibliotecas españolas. Apuntes históricos y noticias bibliográficas sobre fondos y colecciones Vicent García Editores, Valencia, 1996. Pp. 12.

15. Galiano Pérez, A. «Justo García Soriano y el Museo de Orihuela (1936-1939)» en Homenaje a Justo García Morales. Miscelánea de estudios con motivo de su jubilación, ANABAD, Madrid, 1987. Pp. 763-786; así como Girona Albuixech, A. «La Guerra civil en la Provincia de Alicante (1936-1939)» en Historia de la Provincia de Alicante. Historia de la provincia de Alicante: Tomo V: Edad Contemporánea. Siglo XX, Mediterráneo. Murcia, 1985. Pp. 245-300. 
-inevitable por otra parte- a la hora de restituir a sus dueños dichos fondos hacia $1942^{16}$.

Pero no era la primera vez que la biblioteca iba a verse desvirtuada respecto a su composición. Como sucede casi siempre que se pretende analizar una biblioteca institucional, tampoco se sustrajo a las consecuencias de los diferentes procesos de orden político y económico que se sucedieron en los siglos XVIII y XIX. Sucesos de enorme repercusión desde el punto de vista bibliográfico, pues fueron el origen de la segmentación y dispersión de muchos conjuntos librarios, e impulsores de las reincorporaciones y fusiones con otras librerías. Efectivamente, fuimos observando como la biblioteca no se quedó al margen de esos acontecimientos históricos tan significativos que se concretaron con las anexiones de las librerías de los colegios de la Compañía de Jesús en Alicante y Orihuela, al Seminario. La Real Orden de Carlos III sobre la creación de bibliotecas públicas episcopales ${ }^{17} \mathrm{y}$ su inmediata aplicación en la capital del Bajo Segura por parte del obispo Tormo, le afectó por cuanto que años después también sería incorporada al instituto eclesiástico; como tampoco escapó -aunque en menor medida- de los efectos de las medidas desamortizadoras decimonónicas; pues asimismo acoge obras que antaño nutrían las librerías de otras órdenes regulares, ingresadas fundamentalmente a través de donaciones y legados particulares.

$$
* * * *
$$

Pero una cosa es la perspectiva formal y descriptiva, catalogar y reconstruir sus fondos bibliográficos, investigar sus orígenes a partir de los propios ejemplares y, otra muy diferente, intentar vislumbrar las posibles motivaciones en sus adquisiciones y/o recepción en las donaciones -puesto que nada podíamos comentar respecto a otras formas de suministro de la biblioteca-. Obedecieron a tantos y tan diversos factores y determinaciones personales, fundacionales, ideológicas, culturales, educacionales, políticas, etc. que intentar concluir algún resultado en este aspecto se tornaba una espinosa tarea; de ahí que la emprendiéramos sin mucha fruición y con no pocos temores.

Para el estudio de su fondo bibliográfico intentamos desbrozar - y a la postre amalgamar- el mundo del texto, el mundo del libro y, en la medida de las posibilidades ofertadas, el mundo del lector ${ }^{18}$. En primer lugar, analizar los contenidos de la librería supuso que determináramos agrupar las obras por grandes bloques temáticos, lo que nos permitiría una mejor evaluación de esos textos. Respecto a la clasificación

16. En 1936 el edificio fue incautado y pasó a ser cuartel de milicias, convirtiéndose poco después en recinto carcelario de ambos bandos el espacio de la biblioteca. Hacia 1941-1942 se procedió a su devolución a la Diócesis de Orihuela-Alicante.

17. Establecimiento de un fondo para costear la expedición de bulas de los Arzobispos y Obispos: reserva de alhajas para el uso de los Prelados y de libros para bibliotecas públicas. Libro II, Título XIII, Ley $\mathrm{V}$ de la Novísima Recopilación de las Leyes de España Madrid, 1976.

18. Sobre esta cuestión véase el ensayo de Chartier, R. El orden de los libros. Lectores, autores, bibliotecas en Europa entre los siglos XIV y XVIII. Gedisa, Barcelona, 1994. 
temática, optamos no tanto por adoptar, sino más bien por mantener los parámetros de la época, aunque adaptada a los contenidos de nuestra librería. Esto obedeció a que la organización de las obras en los estantes, cuando comenzamos esta investigación, estaba estructurada atendiendo a la que se le había dado en el Seminario según los criterios que prevalecían en 1942, cuando se llevó a cabo la reorganización de la biblioteca al ser devuelta a san Miguel; no subordinándose dicha estructuración a la realidad de la librería más que en una pequeña parte, a consecuencia de una confusión del fondo librario antiguo con el moderno, así como al escaso rigor con que estaban organizados los libros en los armarios; producto, seguramente, de la laxitud con que se producían los préstamos y las devoluciones a sus estantes.

Comentar un fondo librario a partir de una taxonomía preconcebida entraña muchas dificultades. Una cosa es analizar una biblioteca en función de un ordenamiento a posteriori y desde fuera; y otra, describirla con relación al uso que se hacía de los libros contenidos en ella, aunque a veces los objetivos puedan ser comunes y coincidan. Por motivos similares, esas mismas clasificaciones ya establecidas, aplicadas a una librería vinculada a un centro educativo reflejan sólo una parte de las inquietudes culturales y/o espirituales de la institución propietaria y, en menor medida, las de sus lectores potenciales; únicamente nos muestra el orden de los textos y las lecturas vinculadas, en mayor o menor grado, a los saberes a los que había que acceder; al menos a los consensuados y planificados. Las clasificaciones nos resultan válidas para establecer un orden y una primera manera de abordar un conjunto de libros, así como pueden ser indicadoras de determinados parámetros culturales respecto a un lugar y un tiempo dados; pero las cifras que nos traducen no nos permiten conocer cómo se aproximaban realmente a ellos sus lectores y, en nuestro caso, menos todavía saber cual era la aplicación pedagógica concreta de muchas de ellas.

La situación de mezcolanza de fondos que más arriba comentamos -harto habitual, por otra parte, en prácticamente todas las provincias españolas- no hacía sino confirmar los graves inconvenientes que conlleva el estudio de las bibliotecas institucionales; especialmente a la hora de ponerlas en relación con los establecimientos que hoy día las albergan y valorar aspectos vinculados a las mentalidades, el gusto y la formación cultural derivados de un estudio en profundidad. En relación a lo expuesto, ¿hasta qué punto los libros de san Miguel nos permitían establecer diferencias claras, distinguiendo las sucesivas sub-bibliotecas o legados anexionados?. Para el caso que nos ocupa, el catálogo y descripción individualizada de los ejemplares nos posibilitó la identificación de dos grandes conjuntos institucionales: los de las librerías de la Compañía Jesús en Alicante y Orihuela, así como el de la Biblioteca Episcopal de la capital de la Vega Baja, amén de varios legados y donaciones procedentes de individuos relacionados con el cuadro rectoral y profesoral del centro, entre otros.

El siguiente paso trataba de atisbar no sólo la intencionalidad de la institución a la hora de recibirlos, sino a qué pudo obedecer ésta. Al tratarse de un establecimiento erigido en el siglo XVIII, no debíamos descartar que, tal vez, las obras de los siglos XV y XVI se custodiaran por el mero deseo de atesorarlas, por cierta consideración 
estética, o porque, también en esa misma dinámica, se hubiera convertido en una biblioteca-depósito que garantizara la buena custodia y conservación de los legados. Desde nuestra perspectiva actual, rastrear el proyecto inicial de elección de libros y si hubo criterios institucionales prefijados, fue una tarea que no pudimos culminar -apenas emprender- por la ausencia de la documentación a la que hacíamos referencia. Pero tampoco perdimos de vista que el principio rector básico en la constitución de la biblioteca debió ser -y de hecho fue- la utilidad, en relación con el doble objetivo de la creación del Seminario: colegio para formación de los seminaristas y alumnos porcionistas, así como retiro de clérigos; al criterio educacional y formativo le sumaríamos el de cubrir las necesidades espirituales del clero, en función de las reformas propugnadas desde más altas esferas ${ }^{19}$. De nuevo, como podemos observar, iban cobrando nuevas formas nuestras primeras sospechas acerca de la biblioteca y que la institución que la acogía era determinante para poder entenderla.

Otro criterio, mucho más complejo y derivado del anterior, fue el de la fidelidad a una determinada línea de pensamiento, en función de las corrientes ideológicas y culturales dominantes. Para analizar esta situación se hizo imprescindible trazar las biografías de los obispos que más hicieron por el centro en el siglo XVIII: Juan Elías Gómez de Terán ${ }^{20}$-fundador del Seminario- y José Tormo. Durante el pontificado del primero estuvo siempre presente su formación humanística y su filojesuitismo, que se demostraría, no sólo con el diseño de unas Constituciones del centro que contemplaban un plan de estudios imbuido en el espíritu de la Ratio Studiorum de la Compañía de Jesús, sino con el equipo de formadores que lo rodeó, de cuyas bibliotecas -al menos de una pequeña parte- se nutre el centro, y que están impregnadas de ese espíritu humanista que comenzaría a reclamarse desde los círculos ilustrados unos años más tarde. El ingreso de las obras de Arias Montano y las ediciones de los clásicos por parte de otros humanistas como Lipsio, amén de las obras de terceros con no menos resonancia como Sylburg, Glarean, Alberti, Filelfo etc. son bien ilustrativas de esta etapa.

Por lo que al obispo Tormo se refiere, su educación en la Universidad de Valencia y el círculo de personalidades -especialmente clérigos- que frecuentó en la capital del Turia y en Madrid -Bertrán, Climent, etc. ${ }^{21}$ - hemos constatado que influyó mucho más de lo que hasta la fecha se ha escrito. Su figura, no exenta de controversia por lo dispar de algunas de sus actuaciones, un manifiesto talante rigorista, así como su anti-

19. Descripción, Constituciones y Ordenanzas... Op. Cit. Pp. 16-27.

20. Obra clásica para conocer la biografía de este obispo es Vidal Tur, G. Un obispado español. El de Orihuela-Alicante 2 vols. Alicante, 1962; así como Rico Estasen, J. Los restos del obispo Gómez de Terán Alicante, 1958. En torno a algunas de sus actuaciones en la Diócesis y el Seminario, cabe citar: Cabanes Catalá, M.L. «El Seminario de Orihuela durante los episcopados de Juan Elías Gómez de Terán y José Tormo« en V.V.A.A. Orígenes del Seminario.. Op. Cit. Pp. 56-62.

21. Sobre las relaciones de Tormo con el grupo valenciano, puede consultarse: Mestre Sanchís, A. «Un grupo de valencianos en la Corte de Carlos III» en El mundo intelectual de Mayans, Valencia, 1978. Pp. 215-240. 
jesuitismo -siempre destacados a la hora de trazar su perfil ${ }^{22}$ - también tuvo sus ecos en la Diócesis y el Seminario. Pero más decisiva fue la otra faceta del obispo: sus inquietudes culturales, religiosas y su afán reformista, que contribuyó decisivamente al incremento y mejora de la biblioteca. Esa suerte de dualidad para con los estudios del centro se mostró, por ejemplo, al disponer unos textos «oficiales» para el alumnado; pero permitiendo otras lecturas sin duda mucho más progresistas y avanzadas, especialmente en materia filosófica ${ }^{23}$. El seguimiento, casi a la letra, de muchas de las enseñanzas que postulaban los ilustrados, como la creación de la Cátedra de Griego en $1782^{24}$, la obligatoriedad de la lectura de Luis de Granada para Oratoria ${ }^{25}$-reforzados con una larga lista de nombres, que tuvieron cabida en la biblioteca- lo convierten en el personaje clave de la segunda mitad de siglo XVIII en el centro eclesial.

$$
\text { * * * * * * }
$$

Volviendo sobre las clasificaciones, partimos de la clásica y cercana división en Religión y Teología, Historia, Bellas Letras, Derecho, y Ciencias y Artes. Optamos por fraccionar en segundas divisiones únicamente el fondo de Religión y Teología ya que, dada su amplitud -casi el 63\% de las obras catalogadas-, la exposición así lo requería; pero en los restantes apartados estas parcelaciones están más desdibujadas, puesto que las subcategorías impuestas desde la contemporaneidad con los condicionantes, método y fundamentos que gravitan sobre nuestra formación, la mayoría de veces no hacen sino repetir e incidir en las dificultades expuestas ${ }^{26}$. A partir de estas

22. Florensa, J. «Filosofía en la Universidad de Valencia (1733-1787) según los opositores a la cátedra de Filosofía» en Analecta calasancia, $N^{\circ} 21$ (1969), pp. 102-212; véase, asimismo: Martínez Gómis, M. La Universidad de Orihuela... Op. Cit. T.II. Pp. 138-139.

23. Sirvan a modo de ejemplo las declaraciones del que fuera alumno del centro, Juan Sempere y Guarinos, sobre «el muy rigido examen público» para revalidar sus cursos de Filosofía, la cual «(..) según la mente de santo Tomás tuvo que ilustrar con varios principios y tratados de Física moderna y algunas proposiciones matemáticas del Padre Tosca» Cfr. Rico Giménez, J. De la llustración al Liberalismo. El pensamiento de Juan Sempere y Guarinos. Alicante, Universidad, 1997. Pp. 40.

24. Descripción, Constituciones y Ordenanzas... Op. Cit. Pp. 63.

25. Sobre esta cuestión puede consultarse León Navarro, V. Luis de Granada y la tradición erasmista en Valencia en el siglo XVIII Alicante, Diputación, 1986.

26. En torno a este asunto nos parecen muy elocuentes las palabras de F. Bouza Alvarez, quien comenta: «Una de las mayores dificultades que encuentra quien desea estudiar las bibliotecas clásicas, en especial las de la Alta Edad Moderna, tiene que ver más con un precondicionante epistemológico que pesa sobre la propia formación del investigador que con la disponibilidad o no de suficientes fuentes documentales para el trabajo que pretende llevar a cabo. De forma consciente o, por lo general, inconsciente el historiador se enfrenta a un fenómeno tan especifico como éste cargado de categorias contemporáneas que, a la postre, entorpecen más que ayudan a la correcta comprensión del sentido que tuvieron las antiguas colecciones de libros» Cfr. en Del escribano a la biblioteca Síntesis, Madrid, 1992. Las clasificaciones en pp. 124-132. En este mismo sentido también se pronuncia J. A. Alcáin: «Es indiscutible que la dificultad principal que han de afrontar las clasificaciones es la que proviene del cambio que sufren las ciencias con el paso del tiempo. Es dificil que coexistan en una misna clasificación esquemas mentales de épocas distintas» Cfr. «Clasificación Decimal Universal y Teología» en De libros y Bibliotecas. Homenaje a Rocío Caracuel, Universidad de Sevilla. Sevilla, 1994. Pp. 23-36. 
divisiones, las obras son comentadas desde diversos puntos de vista y siempre en función de las posibilidades que nos ofrecen los propios ejemplares, de ahí que las perspectivas de enfoque no sean a menudo homogéneas, como tampoco lo son las noticias que ellos nos proporcionan. $Y$ es que, invirtiendo la denominación de Christian Bec, nuestros libros parlantes no siempre hablan por igual, ni la información que ellos nos proporcionan es a veces suficiente. Una simple mutilación de portada puede suponer el sesgo de algo más que la fuente principal de información de una obra; cuando se carece del apoyo documental suficiente, puede dar al traste con la no siempre sólida arquitectura de reconstrucción complementaria que se entabla a partir de las notas de posesión, la mayor parte de las veces ostensibles en la portada.

Los peligros, por lo tanto, que entrañan los estudios de estas características son notables, somos conscientes de ello; especialmente cuando no se puede establecer fehacientemente a partir de un corpus documental qué títulos, autores y ediciones concretas se localizaban en sus anaqueles en cada momento. Es por ello que, escudriñando a través de las notas de posesión, nos hemos centrado en aquellos ejemplares cuyos ex libris y anotaciones manuscritas nos permiten fijar su ingreso en el Seminario en el siglo XVIII; además de habernos servido del inventario de obras del Colegio de la Compañía en Orihuela -el cual hemos ido cotejando con los ejemplares hoy día conservados en san Miguel-, para delimitar temporalmente dichos ingresos. De tal suerte que el estudio de las obras no obedece a un único criterio; se entremezclan y comentan cuestiones relativas a los textos, a las ediciones, a los autores, a las corrientes ideológicas o doctrinales en las que tradicionalmente han sido englobados, a su interés pedagógico o al gusto que suscitó su lectura, así como a su parcelación como texto básico o complementario sobre el cual gravitaban los estudios, ya fuera en el Seminario o en el resto de establecimientos docentes. Sobre este último aspecto hemos procurado ceñirnos a los estudios que se impartían en la ciudad de Orihuela, pero no por ello hemos obviado las comparaciones -ya sea por discrepancis o por convergencia- con otros establecimientos docentes del territorio peninsular o europeo.

La Biblioteca de san Miguel despuntó especialmente en cuanto al fondo de contenido religioso y teológico, sobre todo en sus disciplinas bíblico-patrísticas, así como en la escolástica renovada del siglo XVI. La fama que adquirió el Seminario por sus estudios, especialmente de Teología, así como la dedicación y constante preocupación de prelados y formadores por la docencia, podría explicar el interés como institución por potenciar su biblioteca, con el fin de atraer a un estudiantado con escasa capacidad para acceder a tratados de cierta altura. De este modo, una biblioteca que contuviera, tanto las novedades doctrinales, como los textos clásicos de la ciencia teológica, bien pudiera haber sido -al mismo tiempo- un excelente reclamo para promocionar su establecimiento formativo; máxime teniendo en cuenta que el mercado tipográfico y librario de la ciudad no se estima que fuera especialmente boyante, a la par que resultaba insuficiente de proporcionar textos de envergadura ${ }^{27}$. En este senti-

27. Esta afirmación, no obstante, hemos de efectuarla con cautela ya que no existe hasta el presente ningún estudio que contemple con detenimiento las relaciones entre el negocio impresor y el librero, los 
do no podemos olvidar que las Constituciones, pese a ser excesivamente parcas en sus indicaciones hacia la librería, recogían la obligatoriedad de los teólogos de acudir a la biblioteca; una buena consecución de la carrera obligaba a un grado de erudición mayor, impensable sin un bagaje de lecturas en que argumentar sus ejercicios y tesis. A los profesores, de igual modo se les suponen estas necesidades bibliográficas, ya que el reglamento refleja que «tengan necesidad, en razón de su magisterio de ver autores o para el más fácil método de su enseñanza» ${ }^{28}$.

Con relación a lo expuesto, la importancia de la Biblioteca del Seminario quedaría magnificada si atendemos al hecho de ser una institución creada en el siglo XVIII; por lo tanto, poseer una nutrida representación de las obras más significativas de la ciencia teológica para los siglos consignados, sería indicativo de ciertas inquietudes intelectuales ${ }^{29}$. Ahora bien:

- ¿Podemos mantener esta hipótesis sin poder demostrar que hubo una voluntad firme en la adquisición o recepción de esos textos, incluido el legado que sobre estas materias se incorporó con la anexión jesuítica?

- ¿Podríamos considerar como seña inequívoca de intencionalidad, de un ingreso reflexionado, los libros que superaron el «expurgo» a que se sometió la librería de la Compañía en Orihuela por dictado de Tormo quien, en virtud de su rigorismo moral, obligaría a censurar la librería jesuítica antes de ubicarla definitivamente en san Miguel?

- Esta altura intelectual ¿se mantendría si el papel de la biblioteca se redujese a la de mero receptor, custodio y conservador de unos textos cuya utilidad práctica e inmediata -en principio- era poco significativa, puesto que estas obras eran representativas de unas corrientes de pensamiento ya en desuso?

- De limitarse la biblioteca a centro depositario, ¿se hizo con una intención superior: la de acaparar «todo el saber teológico», más allá de corrientes, doctrinas e ideologías?

Para contestar -al menos parcialmente- a algunas de estas formulaciones no debíamos pasar por alto los referentes culturales y religiosos del siglo XVIII, así como sus propuestas de renovación de cara a la educación en estos centros y universidades.

establecimientos de venta, la envergadura de los mismos, etc. Pese a lo dicho, datos aislados parecen confirmar que las librerías no eran buenos negocios en Orihuela y que éstas sólo abastecían en una mínima parte las necesidades de sus clientes, ya fueran particulares o instituciones.

28. Descripción, Constituciones... Op. Cit. Pp. 69.

29. A modo comparativo, resultan llamativas las palabras de J. Burgos Rincón respecto a las bibliotecas barcelonesas de la primera mitad del siglo XVIII:«(...) A pesar del amplio espectro de posiciones teológicas existentes, la variedad en el contenido de las bibliotecas de los años 20 y 60 no es precisamente una de sus principales caracteristicas. Unicamente en algunas de las de mayor envergadura se encuentran vestigios de las polémicas del siglo anterior...». Un poco más adelante insiste sobre esta misma cuestión afirmando: «Respecto a las referencias bibliográficas de mayor altura intelectual que protagonizaron las polémicas teológicas de los siglos XVI y XVII, el resultado ha de ser calificado de desalentador» Cfr. en «Los libros privados del clero. La cultura del libro del clero barcelonés en el siglo XVIII» en Manuscrits, 14 (1996) Pp. 231-258. 
A medida que se avanza en los estudios sobre el siglo XVIII, y más concretamente sobre la Ilustración española, se va ponderando más el importantísimo influjo del siglo XVI en la concepción cultural y religiosa de los ilustrados, al tiempo que aumentan las investigaciones sobre el papel que jugaron otros ascendientes europeos, como Italia o Alemania y, por supuesto, el de la propia herencia hispánica, muy especialmente de los escritores españoles del Siglo de Oro ${ }^{30}$. Las concomitancias entre los siglos XVI y XVIII han sido recogidas por diferentes autores, entre los que destacan Antonio Mestre y François López. Son estas referencias y estos paralelismos entre ambas centurias, los que llevarían a Helman a afirmar que la Ilustración española era un «Re-nacimiento, una continuación directa de la manera de pensar y sentir del siglo $X V I\rangle^{3}$.

Las lecturas de los trabajos de estos historiadores nos permitieron una mejor aproximación al fondo librario de san Miguel y que procuráramos no perder de vista la valoración de los precedentes renacentistas -y por ende, clasicistas-, respecto del movimiento ilustrado, al que tampoco se sustrajo el Seminario. Así pudimos comprender y apreciar que la significación de determinados autores y textos del siglo XVI, presentes en una biblioteca como la nuestra, creada en el siglo XVIII, no obedecía a esa simple consideración estética y que los libros no estaban allí ubicados y arrinconados como vestigios del pasado; muchos de esos autores y textos tenían una trascendencia y utilidades concretas, ya que actuaban como referentes de unas actitudes religiosas y culturales reclamadas desde los postulados del movimiento ilustrado. Estas alusiones se percibían de manera especial en las obras contenidas en las disciplinas de Religión y Teología, así como en algunas de las englobadas bajo los epígrafes de Historia y Bellas Letras; toda vez que el conjunto librario denota una continuidad, coherencia y homogeneidad para estas materias que nos permite, al mismo tiempo, establecer una relación con estas enseñanzas en la ciudad.

En este sentido, el análisis descriptivo de los ejemplares de la biblioteca conciliar nos ha revelado que para estas mismas disciplinas el Seminario seguiría una suerte de eclecticismo, ya que no siempre se alude a ellos en los planes de estudio como

30. La bibliografía sobre este aspecto es, ciertamente, fecunda. Nos remitiremos, por simplificar las citas a: López, F. Juan Pablo Forner et la crise de la conscience espagnole al XVIIIe siècle Inst. d'Etudes Ibériques et Ibéro-américaines de l'Université de Bordeuax, 1976; Mestre, A. Ilustración y reforma de la Iglesia. Pensamiento político-religioso de D. Gregorio Mayans y Siscar (1699-1781). Valencia, 1968;- «Los humanistas españoles del XVI en la religiosidad de los ilustración valencianos» en Hispania Sacra, Inst. Enrique Flórez, CSIC. Madrid. Vol. XXXIII (1981), pp. 229-273; Del Pino Díaz, F. «Siglo de Oro castellano e ilustrados españoles (o las raíces europeas del proceso hispano de identidad cultural)» en Álvarez Barrientos, J. y Checa Beltrán (Eds.) El Siglo que llaman ilustrado. Homenaje a Francisco Aguilar Piñal. CSIC, Madrid, 1996. Pp. 713-722; así como V.V.A.A. «El mundo hispánico en el siglo de las luces. Actas del Coloquio Internacional», Unidad y diversidad en el Mundo Hispánico del siglo XVIII (Salamanca, 9-1/ de junio de 1994). 2 vols. Madrid, 1996.

31. De estas cuestiones se hace también eco Egido, T. «La religiosidad de los ilustrados» en Menéndez Pidal (Dir.) Historia de España: Vol. XXXI(1): La época de la Ilustración Madrid, 1992. 
textos recomendados ${ }^{32}$, a veces siquiera como lecturas secundarias, pero lo cierto es que gran parte de las obras figuraba entre las de consulta más o menos frecuente. Lo interesante no es únicamente su utilización, sino que ésta se materialice sobre las ediciones del siglo XVI; hecho que muy probablemente obedezca al déficit de ediciones impresas con posterioridad ${ }^{33}$. Las lecturas y «trabajo» sobre ejemplares impresos en el Quinientos quedan patentes a tenor de las anotaciones y subrayados manuscritos que algunos de ellos portan, las mutilaciones que sufren -con frecuentes pérdidas de las primeras y últimas hojas del texto- las reencuadernaciones y restauraciones a que fueron sometidos, etc.

Asimismo existe un evidente interés por las disciplinas bíblico-patrísticas, importantes no sólo en la formación teológica sino de cara a la preparación espiritual, moral y sobre todo a la predicación; por cuya reforma se aboga insistentemente en el XVIII, y cuya significación no podía entenderse sin un profundo conocimiento de los Padres de la Iglesia. Estos, junto con la Biblia, se presentan como las fuentes auténticas de conocimiento de la Religión y la Iglesia; ocupando ambas un lugar destacado en la biblioteca, aunque la primera lo haga, especialmente, a través de exégesis, paráfrasis y glosas a los textos bíblicos, a cargo tanto de autores vinculados a la corriente humanista, como a la Teología surgida de la Reforma Católica.

La Biblioteca del Seminario contiene, como era preceptivo, escritos relativos a la Historia de la Iglesia, sus tradiciones, Concilios y Sínodos. Pero en exiguo número para los siglos estudiados, respecto a la proporción existente en periodos posteriores. La Historia profana, por el contrario, abunda; polarizándose entre la Historiografía española del siglo XVI -Zurita, Blancas o Mariana- y los clásicos grecolatinos, con los que -siguiendo la costumbre- se aplicaban los alumnos en los rudimentos de la Lengua latina y posteriormente en materias propiamente eclesiásticas. Entre los autores más destacados de esta parcela citaremos la edición que de la Opera de Jenofonte llevó a cabo uno de los humanistas que más se esforzaron por la recuperación de la cultura clásica, Francisco Filelfo; o bien los comentarios a la obra de Polibio a cargo del jurisconsulto francés, François Hotman; uno de los escasos representantes en la biblioteca de la corriente del mos gallicum.

Los clásicos sentaron las bases de los Studia Humanitatis y fueron «puestos en circulación» por Europa desde las postrimerías del Trescientos gracias a los humanistas, acompañados de un número nada despreciable de escritos de los propios huma-

32. Similar tendencia observa C. Mas Galvañ para el Seminario de san Fulgencio de Murcia. Vid. «De la Ilustración al Liberalismo: el Seminario de san Fulgencio de Murcia (1774-1823)» en Trienio, № 12 (1988), pp. 102-175.

33. El recurso a Ios autores más representativos de la Escuela de Salarnanca podría estar en clara consonancia con la postura defendida por ilustrados como Climent, Obispo de Barcelona. Vid. Martín Hernández, F. «La formación del Clero en los siglos XVI y XVII» en Mestre Sanchís, A. (Dir.) La Iglesia en la España de los siglos XVI y XVII. Vol. IV, Historia de la Iglesia en España, Madrid (1979). Acerca del uso de las ediciones del Quinientos en siglos posteriores y el déficit de ediciones de ciertas obras resulta de indudable interés: Juárez Medina, A. Las reediciones de obras de erudición de los siglos XVI y XVII durante el siglo XVIII español. Lang, Frankfurt am Main; Bern, New York; París, 1988. 
nistas ${ }^{34}$; contribuyendo la imprenta a esa difusión, al reproducir en cantidades mayores esos textos y facilitando en acceso a más libros. Entre los escritos de éstos sobresalen los de Justo Lipsio - cuyas obras exhiben los anaqueles de manera generosajunto con las de Arias Montano, en cuidadas ediciones facturadas por Cristóbal Plantino. Centrándonos en los representantes de la vertiente filológica de este movimiento, no queremos dejar de citar a Budé, Despauterio, Clenard o Pontano; autores cuyas obras fueron ampliamente consumidas en la Europa del XVI y cuya presencia en el Seminario se explica en términos académicos, por su vinculación a la pedagogía jesuítica.

$* * * *$

Pero, evidentemente, no podíamos tratar todas las obras por igual, la homogeneidad que presentan estas últimas disciplinas no se daba en igual medida en las restantes. De las obras incluidas en las materias comprendidas en Ciencias y Artes, todavía podíamos vislumbrar una relación con la enseñanza de la Filosofía en diversos establecimientos educativos de la ciudad a lo largo de la Edad Moderna; pero no sucedía lo mismo con el resto de áreas -Astronomía, Medicina, Astrología, Arquitectura, etc.- Idéntica situación presentan las obras de Derecho, Legislación y Jurisprudencia, dado que el Seminario no impartía estudios de esta Facultad. En ambos casos, y conforme los propósitos que nos trazamos a la hora de valorar los contenidos de la biblioteca, determinamos conjugar la historia de lo que era leído, consultado, manejado o estudiado; con la forma, la intención y el fin con que se consumía, y a tenor de qué motivaciones, cuando fuera posible determinarlo. De tal suerte que pasamos a comentar dichos apartados en función de unos intereses más amplios, como eran los de las otras instituciones de la ciudad -principalmente educativas- a lo largo de la Edad Moderna, así como la significación que dichas obras habían tenido durante el Renacimiento. Era la única posibilidad que nos permitía la biblioteca considerada desde esas disciplinas como «biblioteca-depósito», cercana a las librerías conocidas y comúnmente denominadas «bibliotecas de aluvión»; entendiendo éstas como aquellos depósitos librarios donde se han ido acumulando los libros -a modo de sedimentos- $\sin$ determinación alguna en sus recepciones, sin un hilo conductor entre éstos y sin que podamos vislumbrar una línea más o menos coherente, respecto a un determinado ideario u objetivos pedagógicos. Así, entre las características más destacadas extraídas del análisis de las obras correspondientes a la materia de Derecho, podemos observar que existe un elevado número de representantes del ordo eclesiástico entre sus propietarios, quienes -especialmente en sus niveles más altos- sentían una especial atracción por este tipo de estudios, puesto que le posibilitarían hacer carrera dentro de la administración eclesiástica ${ }^{35}$. Algunos de los tratados de Derecho catalogados ha-

34. Rico, F. El sueño del Humanismo. De Petrarca a Erasmo Alianza Universidad. Madrid, 1997. Pp. 79.

35. Constata esta misma tendencia Weruaga Prieto, A. Libros y Lecturas en Salamanca: del Barroco a la Ilustración. Junta de Castilla y León. Conserjería de Cultura y Turismo. Salamanca, 1993. Pp. $129-132$. 
bían formado parte de bibliotecas particulares, sobre todo de juristas, heredadas de generación en generación, y en los cuales determinadas familias -especialmente de la baja nobleza o nobleza no titulada- buscaban la justificación de sus propias actuaciones y modus vivendi ${ }^{36}$.

La biblioteca, no obstante, contiene los textos básicos del Derecho canónico, el Decretum de Graciano y las Decretales de Gregorio IX, así como algunas de las partes fundamentales que integran el Corpus iuris civilis; obras jurídicas elementales, que solían ser frecuentes en bibliotecas eclesiásticas. Sin embargo, llama la atención la falta de ediciones glosadas y comentarios, especialmente por decretalistas medievales, por juristas del mos italicum y otros antiguos maestros de la Jurisprudencia como Bartolo de Saxoferrato y Baldo de Ubaldis, por reducirnos a dos ejemplos. Contamos, por el contrario, con la presencia de canonistas insignes como Martín de Azpilcueta y algún otro autor representativo en materia de Derecho civil. Finalmente, no deja de resultar significativo que no se haya constatado la presencia de ningún ejemplar relativo a las compilaciones de Derecho valenciano y otras de entidad local, siquiera recopilaciones generales.

Respecto a las disciplinas contenidas en el apartado de Ciencias y Artes -y al margen de la Filosofía-, para el ámbito de la Medicina la librería objeto de estudio refleja en buena medida la mixtificación de las corrientes preponderantes en el siglo XVI ya que, por un lado, localizamos autores como Arnau de Vilanova y la presencia de obras de carácter enciclopédico medieval en materia médica y terapéutica-léase el tratado de Bartolomé Anglico, por ejemplo-, enraizados con el escolasticismo arabizado de origen medieval, frente a textos -como la edición de Jeremías Drivere, sobre el tratado médico de Celso Aulo Cornelio- que seguirían las pautas del Humanismo médico renacentista, entre cuyos objetivos se hallaba el estudio, comentario y edición de las obras de los tratadistas clásicos. Esta misma dualidad también podríamos hacerla extensiva a otras parcelas del ámbito científico. El contacto con las fuentes clásicas en el terreno de las Matemáticas supondría la recuperación crítica de la obra de Euclides, divulgado por el uso docente de los Elementos o por la inclusión de fragmentos euclidianos en manuales didácticos ${ }^{37}$. El repaso a las obras científico-técnicas revela, asimismo, la existencia de un equilibrio entre la tradición y la modernidad; es decir, junto con vestigios y herencias de la Ciencia de los siglos XIII y XIV, y al lado

36. Durante el siglo XVIII resulta frecuente que las librerías de familias pertenecientes a este grupo social contengan textos legislativos nacionales, repertorios de Derecho nobiliario, además de genealogías y ensayos sobre la formación de la nobleza, como ya pusimos de manifiesto en Oligarquía y Poder en el siglo XVIII. La familia Bourgunyo de Alicante. Inst. «Juan Gil-Albert», Diputación de Alicante, 1994. Pp. 177.

37. Siguiendo a López Piñero, «se erigió en el libro de texto imprescindible para el estudio de la Geometria y las Matemáticas desde las escuelas de la Antigua Grecia hasta las universidades renacentistas» Cfr. en «Humanismo, Renacimiento y Ciencia» en Creadores del Libro. Del Medievo al Renacimiento. Madrid, 1994. Pp. 180-207. La Ratio Studiorum también incluía la explicación a los alumnos de Física de los Elementos de Euclides. Cfr. GIL, E, (Ed.) El Sistema educativo de la Compañía de Jesús. La «Ratio Studiorum» Univ. Pontificia de Comillas. Madrid, 1992. Pp. 155. 
de tratados como La reprovacion de supersticiones y hechizerias de Pedro Ciruelo, representativo de la pugna contra una subcultura científica, conviven una serie de libros que participaban de las corrientes científicas renacentistas, como se demuestra en materia de Ingeniería y Metalurgia con la obra del alemán George Bauer o Agrícola, o el tratado de Arquitectura de Alberti; ambos procedentes de la librería personal del que fuera rector del centro, José Juste, e incorporada al Seminario tras su fallecimiento.

No queremos finalizar este artículo sin hacer una sucinta mención a otros aspectos del trabajo; los referidos a los «aspectos materiales» y «mundo profesional» del libro. El formato, las lenguas de edición o los lugares de publicación predominantes, aunque de forma más breve, también han sido objeto de nuestra atención; para lo cual ha sido indispensable apoyarnos en la cuantificación. La geografía de la producción sitúa -como era previsible- a Lyon, Amberes y Venecia como las principales ciudades exportadoras de los libros objeto de nuestro análisis; sobresaliendo Salamanca, Zaragoza y Alcalá de Henares entre las españolas. Por otro lado, las cifras también nos indican que el mayor número de impresos estudiados se comprende entre los años 1551-1600. Si bien es cierto que esta tendencia alcista viene a coincidir con la multiplicación de los talleres de imprenta y aumento de la producción libraria, no podemos olvidar que los lectores también deciden y marcan estas tendencias. Así, no debemos perder de vista que es un momento en que la Iglesia toma de nuevo las riendas tras años difíciles y lanza la contraofensiva: la Reforma Católica. Es un «género» que interesa en una biblioteca eclesial; de modo que tiene su lógica que contenga más ejemplares de esta especialidad y las cifras lo traduzcan en un predominio de obras para este periodo.

De los grabados que ilustran los libros y las encuadernaciones que portan los ejemplares, también nos hemos ocupado; pero, puesto que estamos tratando el conjunto de las obras de los siglos XV y XVI contenidas en una biblioteca institucional, no podíamos más que seguir las pautas a las que un fondo tan dispar nos posibilitaba: el análisis descriptivo. Somos conscientes que describir el material grabado en los libros podía llegar a convertirse en una «suerte de pasarela» de las imágenes estampadas en dichas obras, pero tampoco teníamos muchas más opciones ${ }^{38}$. De este modo, el primer apartado lo estructuramos conjugando el orden formal del libro, de ahí que comenzáramos con un repaso a las orlas y frontispicios que embellecen las portadas, con una clasificación temática de las representaciones, según se tratase de iconografías descriptivas o simbólicas -divididas a su vez en profanas y religiosas-, a la par que citamos parte del contenido de signos, símbolos, alegorías, emblemas, escudos y marcas de impresor.

38. Metodología similar aplica, por la heterogeneidad de los fondos estudiados, B. García Vega en El Grabado del libro español. Siglos XV-XVIII 2 vols. Valladolid, 1984. 
La encuadernación, por su parte, se limitó a tener un papel protector del libro; una intención meramente utilitaria y acorde con los criterios que regían una institución educadora. Ese fin práctico, el fin utilitario de los libros -priorización del librotexto sobre el libro-objeto- predomina en la biblioteca; lo que se traduce en el numeroso conjunto de obras que ostenta envolturas en pergamino, aunque este criterio no ha tenido porqué «necesariamente» primar sobre un libro concreto a lo largo de su historia. Las obras procedentes de otras bibliotecas particulares e incorporadas al fondo del Seminario pudieron y de hecho muchas de ellas tuvieron la consideración de «bien poseído», de «objeto de arte»; de ahí que sus anteriores propietarios volcaran la necesidad de distinguirlos mediante una estética exterior acorde, con una ligadura en consonancia con esa notoriedad. Las encuadernaciones que analizamos obedecieron, por lo tanto, al interés de sus anteriores propietarios, fundamentalmente bibliófilos y eruditos con economías algo más saneadas, y cuyo amor por el libro y una moderada ostentación les llevó a cubrirlos con envolturas de arte ${ }^{39}$.

La biblioteca es, como avanzamos, una buena muestra del debate entre la oficialidad de los planes de estudio y las lecturas «paralelas»; entre los textos que manejaban profesores y estudiantes por su obligatoriedad, y las lecturas que eran aconsejadas en determinados círculos -pero que oficialmente no constaban-para consolidar una formación e instrucción sólidas entre el clero que se pretendía renovar y el que se estaba educando en el centro, sobre las que nada se decía pero de hecho se utilizaban; entre las vedadas a los estudiantes y consentidas al profesorado - ¿donde estaba el límite?-. La negativa del obispo José Tormo a aceptar las instrucciones oficiales de implantar en san Miguel la lectura de obra del Padre Jacquier -más progresista al armonizar Filosofía y Teología- no implicaba, sin embargo, descartar su lectura y consulta en el recinto colegial, «siempre y cuando fuesen los catedráticos quienes lo manejasen, no los estudiantes» ${ }^{40}$. Esta frase ya es de por sí indicativa de esa suerte de ambiguo criterio - no reglamentado- sobre las restricciones o principios diferenciadores que -suponemos- regirían la biblioteca. Ahora bien, deslindar qué tipo de lecturas concretas estarían al alcance de cuantos las solicitaran y cuáles les estarían vedadas, por tratarse de autores con una componenda filosófica o científica avanzada en exceso, ideológicamente heterodoxos o espiritualmente peligrosos, no podemos saberlo con certeza, pese a suponer que su lectura -permitida al personal docente- muy probablemente se extendiera a los alumnos más avezados.

39. Dicho apartado ha sido objeto de reciente publicación con el título «La encuadernación del Libro renacentista en la Biblioteca del Seminario de Orihuela» en El Libro como objeto de arte. Actas del I Congreso Nacional sobre Bibliofilia, Encuadernación Artística, Restauración y Patrimonio Bibliográfico. Cádiz, 21-24 abril de 1999. Cádiz, Ayuntamiento-Diputación, 1999. Pp. 303-324.

40. A(rchivo) de la C(atedral) de O(rihuela). Expediente sobre el Seminario Año 1784. S/C. Fol. 73 vto. 
La Biblioteca del Seminario no tuvo el carácter de una biblioteca pública, ni nació con la vocación de ser un recinto de libre acceso, como tampoco hubo un interés por divulgar sus fondos; desde el primer momento sus orígenes se presentan confusos. Tampoco existió una normativa sobre cómo proceder en la biblioteca, ni se conoce qué normas regulaban el puesto de bibliotecario, ni cómo era el perfil de quien debía desempeñar dicha tarea. Esa incertidumbre inicial se extiende a lo largo de su historia, ya que las noticias sobre ellas son casi inexistentes. No nos consta que se efectuara un índice de los libros que contenían sus anaqueles, como tampoco hubo pretensión de hacer exhibición de dichas obras, pues nunca fueron identificadas con ex libris o sello del centro hasta la década de los años cuarenta de este siglo, cuando los libros volvieron a ubicarse en ella tras esa estancia temporal en la ciudad, y donde se procedió a identificarlas, al tiempo que se reorganizaron y se efectuó un intento de registro.

Como queda dicho, la librería en ningún momento nació con vocación de publicitarse ni de abrir sus puertas al público en general, aunque tampoco tenemos constancia de que existiera mención expresa de lo contrario; pero, ciertamente, el tiempo le fue acrecentando ese carácter de biblioteca «de la casa» para uso del personal del centro, de los seminaristas y demás personas del entorno eclesial. Quizá la causa de esa individualidad, manifiesta a lo largo de su historia, lo constituya su propia ubicación. Prueba de ello -tal vez algo peregrina, pero no por ello menos cierta- es la propia ubicación del Seminario en lo alto del monte san Miguel. Especie de barrera natural que "protegió» a la biblioteca, y evidentemente al centro, de tal modo que no resulta fácil acceder a ella ${ }^{41}$. En este sentido, recogemos las quejas de J.A. Mingot, funcionario del Ayuntamiento de Alicante en el siglo XIX, quien -pese a la ilusión no disimulada por haber localizado en el Seminario un manuscrito de la Crónica de Alicante de los Padres jesuitas J. B. Maltés y Lorenzo López que se contenía en dicho lugar, a donde fue a parar con el resto de la Biblioteca del Colegio de la Compañía tras la expulsión-, no silenciaba su desesperanza al pensar en el trecho que debía subir diariamente para realizar sus consultas en la biblioteca

«... formamos el propósito de visitar diariamente aquella biblioteca, aún a costa de tener que trepar el empinado cerro sobre el cual levantó el obispo Terán tan grandioso edificio (...) $)^{42}$.

41. En este sentido conviene recordar que entre las «excelencias» proclamadas por Gómez de Terán para ubicar el Seminario en el monte San Miguel era ese relativo aislamiento de la ciudad, justificándolo del modo siguiente: Quanto más difícil es esta alta Ciencia, les es mucho más necesario el retiro al orden de los clérigos, que ha de profesar este estudio (...) y que sigue argumentando a lo largo de varias páginas. Gómez de Terán, E. Constituciones... Op. Cit. Pp. 12-16.

42. Maltes, J.B. y López, L. Ilice ilustrada: Historia de la Muy Noble, Leal y Fidelísima ciudad de Alicante. Alicante, 1991 (Edc. facsimilar del mss. de 1881). fol. 11 r. 